\title{
Airport retailing in the UK
}

Received (in revised form): 13 July 2007

\section{Bob Thompson}

is the Founder of RETRI Group, established in 2001 as a research consultancy in real estate. For the previous 16 years he was a partner at King Sturge. His clients range from Investors and Fund Managers through Developers and Local Authorities. Although most widely published as an expert in industrial property, he has been involved in the whole spectrum of property types, including some of the largest schemes in Europe. He is a past President of the European Real Estate Society, a visiting Research Fellow at Reading University and a Senior Research Associate at the College of Estate Management.

\begin{abstract}
Airport retailing has been highlighted as one of the fastest growing niche retail markets, delivering outstanding prospects for growth over the next five years. Over the past decade, the global airport retailing market has grown very quickly and is forecast to see continued buoyancy. Nevertheless, there are significant risks to this scenario, not the least of which is a growing consensus against air travel led by the environmental lobby. This paper examines the background to airport retailing in the UK using BAA airports as a model and poses the question - should retailers invest at airports?
\end{abstract}

\section{Keywords:}

airports, retail, turnover per $\mathrm{m}^{2}$

Journal of Retail and Leisure Property (2007) 6, 203-211. doi:10.1057/palgrave.rlp.5100067

\section{INTRODUCTION}

Over the past decade, the global airport retailing market has grown by a staggering 87.6 per cent and is estimated to be worth $\$ 23.9 \mathrm{bn}$ in $2006 .{ }^{1}$ After a growth of just over 5 per cent during the five years from 1996 to 2001, the market grew at a rapid 78 per cent during the second half of the last decade.

Usually, from the perspective of real estate, airports feature as a mix of conventional property uses. In the literature, their role as a driver of economic activity is well recorded (eg York Aviation ${ }^{2}$ ). More recently, their role as the focal point of an urban hub - the aerotropolis - has been identified. ${ }^{3}$

Airports have all the classic characteristics of infrastructure

Bob Thompson RETRI Group 44 Stewart Avenue Upminster RM14 $2 \mathrm{AF}$ UK

Tel: +44 (o) 7703234251 E-mail: bt@retrigroup.com investments - relatively high initial costs and risk profile evolving into a stable long-term investment for income. That income stream is where an airport becomes of interest to retailers.

Air travel, the principal driver of income, has grown almost exponentially over the past 20 years or so and is forecast to grow equally fast in the future. The amount of money spent while at the airport has grown quickly and is expected to grow equally fast in the future. 
Demand for airports and airport-related property has seldom been stronger. Airports, as opposed to airlines, are thriving.

Yet all is not rosy in the aviation garden. Decades of nationalistic support for flag-carrying airlines and national airports have begun to unwind, leaving prominent casualties like Swissair and Sabena in their wake.

Mindful of the fact that aircraft are significant polluters, environmentalists have been ensuring that anything to do with air travel has attracted a bad press. Politicians, ever quick to leap onto what they perceive to be a populist bandwagon, have become ever more bold in their condemnation of what is a significant European industry.

From the perspective of a retailer, these risks have to be set against a rosy prognosis of passenger numbers, and by implication spending, increasing much faster at airports than on the High Street.

\section{THE AIRPORT MODEL}

BAA owns Heathrow, Gatwick, Stansted, Glasgow, Edinburgh, Aberdeen and Southampton airports and is itself owned by Spanish company Ferrovial. The company also has stakes in, or management contracts for, six Australian airports, Naples, Indianapolis, Boston, Pittsburgh and Baltimore. Until very recently it was also the majority stakeholder in Budapest airport. This mix of ownerships gives us the opportunity to use BAA as a model for the airports industry for, while it may not be a representative, it should be typical of the developed part of the industry.

What manner of an investment is an airport? Typically, revenue is derived from three main streams:

- Aviation: Airside activities, for example landing fees.

- Commercial: Landside activities such as retailing and catering.

- Property: Rents and sales.

For BAA, aviation represents the biggest earner, but only just. In 2006, it represented 44 per cent of income with commercial interests a close second with 42 per cent. Property was a distant third. Axiomatically, growth in retail spending at airports is a function of the number of passengers passing through and the volume of space available to serve them.

\section{PASSENGER GROWTH}

Forecasts for the future of air travel are very bullish. The latest Airbus Global Market Forecast, ${ }^{4}$ predicts strong industry growth through to 2023 (Table 1), with the need for more than 17,300 new passenger and freighter aircraft.

The forecast expects a three-fold growth in passenger traffic, or an average annual traffic growth in revenue passenger kilometres (RPKs) of 5.3 per cent and the replacement of 9,200 passenger airliners through to 2023. Overall, this period is expected to include the strongest traffic growth seen since 1980 . 
Table I: Growth rates in air freight to 2023 by route

\begin{tabular}{llll}
\hline Inbound route & $\begin{array}{c}\text { Average annual } \\
\text { growth rate (\%) }\end{array}$ & Outbound route & $\begin{array}{l}\text { Average annual } \\
\text { growth rate (\%) }\end{array}$ \\
\hline Africa to Europe & 6.2 & Europe to Africa & 5.0 \\
CIS to Europe & 4.8 & Europe to CIS & 8.3 \\
Asia to Europe & 6.4 & Europe to Asia & 6.2 \\
Central America to Europe & 3.7 & Europe to Central America & 5.5 \\
Indian Subcontinent to Europe & 6.1 & Europe to Indian Subcontinent & 6.0 \\
Japan to Europe & 5.9 & Europe to Japan & 5.2 \\
Pacific to Europe & 4.6 & Europe to Pacific & 4.1 \\
Middle East to Europe & 4.5 & Europe to Middle East & 4.9 \\
PRC to Europe & 7.1 & Europe to PRC & 7.8 \\
North America to Europe & 5.0 & Europe to North America & 4.8 \\
South America to Europe & 4.7 & Europe to South America & 6.1 \\
& & Europe to Europe & 5.0 \\
\hline
\end{tabular}

Source: Airbus

Asia-Pacific region's strong economic development, especially in emerging economies, and the increasing impact of low-cost carriers in all domestic markets will contribute significantly to traffic growth. A total of 32 per cent of the nine trillion RPKs forecast in 2023 will be generated in Europe.

To accommodate this increase in passenger traffic, the number of flights offered on passenger routes and the number of passenger aircraft in service will be more than double in 20 years, accompanied by the use of larger aircraft. Airbus therefore forecasts that the average number of seats per passenger aircraft will increase by 20 per cent from 181 to 215 over this period. ${ }^{4}$

Demand for air travel will result in the expansion of international traffic through the development of new routes, as well as through consolidation of the major hubs. The bulk of the traffic growth will be driven by the concentration of population, wealth and industrial activities as well as the desire for low fares.

The latest forecasts from Boeing ${ }^{5}$ are more recent and slightly more circumspect, predicting that growth in air traffic will run at some 5 per cent per annum, a tad down on their 2004 forecast of 5.2 per cent per year. Air freight is expected to grow at 6.1 per cent per year.

The rise of low-cost carriers is set to continue to generate new travel growth in Europe. European markets have completed their first decade of liberalisation, which has stimulated air travel demand.

Lower fares and point-to-point services to many secondary and select hub airports are desirable to air travellers. Furthermore, inclusive tour charter operators will play a role in delivering air travel for European tourists to a wide variety of destinations, many outside of the continent.

For more specific data relating to Europe, Eurocontrol ${ }^{6}$ produce longterm forecasts of flights, summarising predicted increases in the number of flights per year within Europe and breaking the growth down into particular flows, to indicate which parts of Europe are likely to see which levels of growth. It also lists traffic growth in individual EU states and produces scenarios of possible futures. Rather than producing forecasts in 
terms of passenger numbers or passenger-kilometres, the data are given in terms of total flights. They use four different scenarios describing different oil prices and economic growth, and therefore generate a range of annual increases in flights from 2.3 per cent to 3.4 per cent compared with an average growth of 3.8 per cent per year between 1975 and 2001 . Therefore, they conclude that the number of flights will be increasing at a lower rate in the future.

Within forecasts for 1998-2015 produced by Air Transport Action Group (ATAG) ${ }^{7}$ they predict an average annual growth rate in terms of passenger traffic of 4.3 per cent, with the Netherlands predicted to experience the highest growth of 5.2 per cent per year. Of the top-five countries in terms of passenger numbers, the UK is, however, predicted to be the fastest growing market, moving from 144 million passengers in 1998 to 313 million in 2015.

The UK is also predicted to remain the most important market, followed by Germany and France. In terms of specific regional developments, the Europe to Middle East/Asia market will be the fastest growing at a rate of 5.1 per cent until 2015, and the Europe to Americas market will be the slowest at 4.4 per cent per year reflecting market maturity.

In summary, the EU and the UK are predicted to have continued high growth at around 4-5 per cent in their aviation industries until 2020, with the UK continuing to dominate the European market.

As a manifesto for investing in airport retail property these forecasts could scarcely be bettered. By 2023, the volume of FTKs involving European airports will have risen from around 41 in 2005 to 142 - a growth rate of 250 per cent.

There are, however, some important reasons to treat forecasts of this magnitude with some caution. First, the provenance of the forecasts themselves. Makers of aircraft are unlikely to underestimate demand for their product just as estate agents are unlikely to do so for property. Aerospace is an industry that has long development cycles and long pay-back periods. Future demand has to be strong to ensure current investment. In fairness, the Airbus projections are a notch or two down on historical growth rates. Between 1979 and 2005 passenger traffic grew at around 11 per cent per annum. ${ }^{8}$

Secondly, energy costs are likely to be significantly higher over the next 20 years than they have been in the past. This is likely to impact on these forecasts in two main ways:

- High energy prices act as a brake on world trade — the principal driver of air freight volume.

- Higher energy prices mean higher operational costs. Currently, the price of fuel represents around 36 per cent of operational costs. Fuel price surcharges notwithstanding this can only be passed on to the customer to a limited degree before it begins to affect demand.

Thirdly, the political climate is becoming less favourable. Although currently aviation accounts for around 1.6 per cent of emissions, ${ }^{9}$ carbon dioxide emissions from aviation are expected to grow over threefold in 
the period to 2050, making it among the fastest growing polluters. Set against this context, it seems inevitable that additional taxation of air travel will be implemented in the relatively short term.

\section{RETAIL SPACE}

The commercialisation of airports has been a global trend as any traveller will acknowledge. In what seems like a blinking of an eye, we have moved from a few shops that sold local specialities packaged for tourists in search of that last minute gift to full-service retail malls. The new Terminal 5 at Heathrow will be as much about retailing as it will be about air travel.

Retail has become a massive contributor to airport profits. Heathrow, for example, has $46,000 \mathrm{~m}^{2}$ of retail space, the size of a substantial regional mall. In its seven UK airports overall, BAA has some $98,000 \mathrm{~m}^{2}$ of retailing that contributed over $£ 600 \mathrm{~m}$ in 2006 .

Figure 1 shows the volume of retail space per thousand passengers in a European context. London Gatwick leads the field currently, although this will be eclipsed by Heathrow when the new Terminal 5 adds another $20,000 \mathrm{~m}^{2}$ to the airports retail offering. In second place, Madrid Barajas benefits from the $24,000 \mathrm{~m}^{2}$ added by the new Terminal 4 building. At the bottom of the list, Frankfurt has $9,000 \mathrm{~m}^{2}$ of additional retailing planned for the next few years. This excludes the prospect of a third terminal that would probably take it to the top of the list.

This emphasises the importance of retail income to airports. Clearly, with projections as bullish as they are for passenger throughput, this can only grow and is estimated to reach $£ 2$ bn by 2011 in the UK alone.

As far as airport-related property generally is concerned, performance is driven by three factors:

- Demand created by the throughput of passengers and freight at the airport.

- Demand created by the provision of services at and to the airport.

- Demand for property created by the action of the market served by the airport.

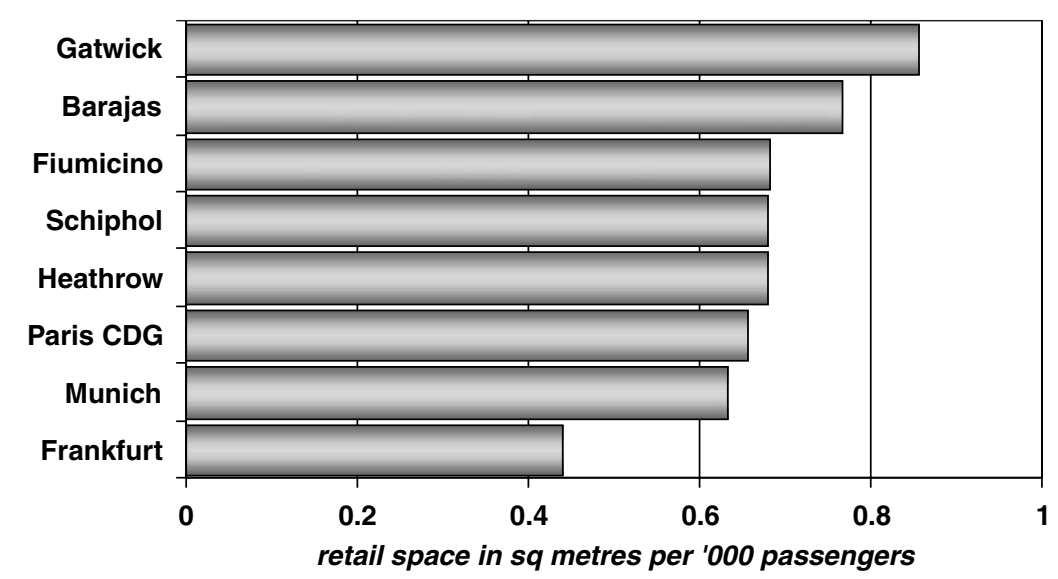

Figure I: Retail space per '000 passengers (square metres) in European airports 


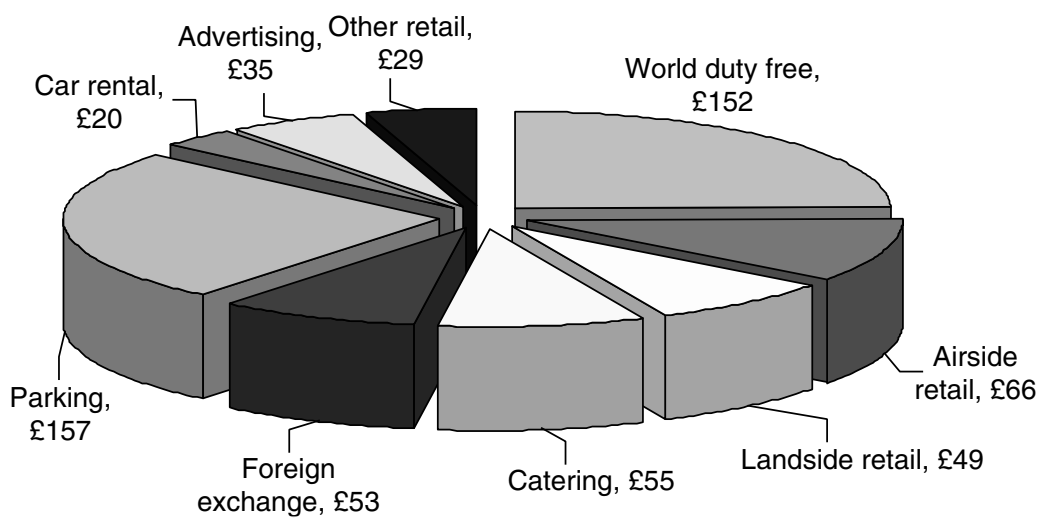

Figure 2: Breakdown of retail income $(\mathrm{Em})$ at BAA UK airports by type in 2006

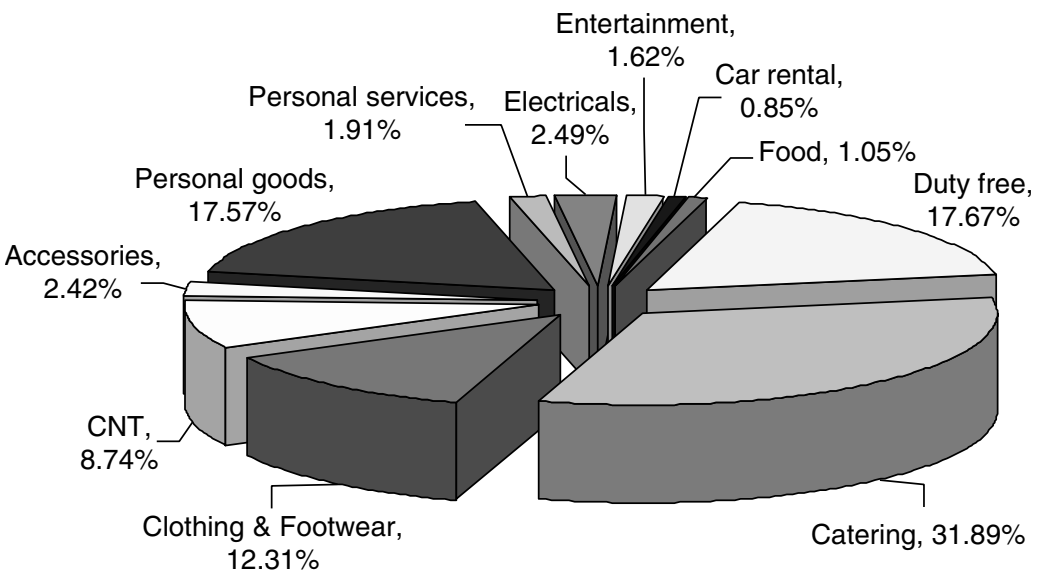

Figure 3: RETRI group estimates of floorspace at BAA UK airports by broad retail category (per cent of total)

Retail property thrives on the former two criteria, but the third begs the question as to whether airports provide a retail function to the wider community.

Figure 2 shows a breakdown of retail income at BAA UK airports by type. Landside retailing, that is, with public access, accounts for only around 20 per cent of total retail income overall, indicating that it is probably the exclusive preserve of passengers and staff.

For conventional High Street retailers, Figure 2 shows that, once specialist offers like car hire and catering plus exclusive franchises like duty-free are stripped out, turnover becomes a much less impressive $£ 115 \mathrm{~m}$.

Figure 3 shows RETRI group estimates of the floorspace at BAA's UK airports by broad retail category. As would be expected, personal goods and accessories account for some 20 per cent of the retail offer, followed by Clothing \& Footwear, mainly in upmarket brands, and CNT including books. Electricals only account for around 3 per cent and Food a tiny 1 
Table 2: Income at BAA's UK airports

\begin{tabular}{|c|c|c|}
\hline & NIPP & NIPSM \\
\hline Heathrow & $£ 3.03$ & $£ 4,442$ \\
\hline Gatwick & $€ 2.84$ & $€ 3,322$ \\
\hline Stansted & $£ 2.57$ & $£ 4,747$ \\
\hline Glasgow & $£ 2.51$ & $£ 4,247$ \\
\hline Edinburgh & $£ 2.56$ & $€ 4,354$ \\
\hline Aberdeen & $£ 2.51$ & $£ 4,543$ \\
\hline Southampton & $£ 2.93$ & $€ 7,794$ \\
\hline
\end{tabular}

NIPP, Net income per passenger; NIPSM, Net income per square metre

Table 3: Income at BAA's UK airports

\begin{tabular}{llc}
\hline & NIHSRPP & NIHSRPSM \\
\hline Heathrow & $£ 0.90$ & $£ 2,474.82$ \\
Gatwick & $£ 0.95$ & $£ 2,475.92$ \\
Stansted & $£ 0.61$ & $£ 2,479.79$ \\
Glasgow & $£ 0.38$ & $£ 2,460.85$ \\
Edinburgh & $£ 0.60$ & $£ 2,467.34$ \\
Aberdeen & $£ 0.38$ & $£ 2,483.07$ \\
Southampton & $£ 0.16$ & $£ 3,061.22$ \\
\hline
\end{tabular}

NIHSRPP, Net income from High Street retail types per person; NIHSRPSM, Net income from High Street retail types per square metre

per cent mainly at Heathrow and Gatwick. This provides commentary upon the popularity of the different offers:

- Duty-free generates 36 per cent of the revenue from 18 per cent of the space.

- Car Hire generates 5 per cent of the revenue from 1 per cent of the space.

- Catering generates 13 per cent of the revenue from 32 per cent of the space.

\section{TURNOVER}

The main parameter used by airports to assess retail success is net income per passenger (NIPP); however, a more useful measure for retailers would be net income per square metre (NIPSM).

Table 2 shows both parameters based upon RETRI Group estimates ${ }^{10}$ using BAA data. Given the minimal food retailing available, this relates primarily to comparison retailing. At $£ 7,794$, the highest NIPSM shown here - Southampton - would grace a city centre, and this is achieved through the smallest retail area $\left(700 \mathrm{~m}^{2}\right)$ of any of the airports analysed here. All the other airports with the possible exception of Gatwick reach comparable good quality town centre turnovers.

What is, perhaps, more interesting is the difference between the different airports. With exception of Southampton where key categories are absent, why do the NIPSM figures vary by as much as 25 per cent? A further breakdown provides an explanation. 
Analysis of the commercial data by retail type shows a very different picture. Table 3 shows the same parameters when conventional High Street comparison retail categories ${ }^{11}$ are extracted from the data.

By this standard, airport retailing offers the levels of turnover per square metre seen by local or district centres, and the airports are all seeing very similar levels of activity. Propensity to buy duty-free goods provides the differentiator between the BAA airports.

\section{CONCLUSIONS}

So should retailers invest in airports? That rather depends on the type of retailer. Overall, this data would seem to indicate that airports do not perform at anything other than local or district centre level in terms of retail turnover. Airports are, however, about brand exposure and many upmarket fashion brands, for example, may not be able to afford not to have a presence in the terminal building. Furthermore, widespread use of turnover rents at airports lessens the sting of less than stratospheric performance.

Going forward, prospects look strong for growth in passengers and, by implication, retail volume but the threats to these forecasts are real.

In isolation, airports and their activities represent a small proportion of the overall carbon output, particularly by comparison with other modes of transport. It would be, however, disingenuous to pretend that this is insignificant, especially given the almost exponential rates of growth projected for the next 20 years. There is no doubt that the relatively free ride given to aviation over the past 40 years has ceased and that the industry will have to make a significantly higher contribution to the whole cost of flying in the future.

This may have a negative impact upon the forecast rates of growth in air travel but this throws up another conundrum. Airlines need to be profitable to invest in the new planes that deliver the environmental benefits. If increasing taxes on air travel cause this flow of investment to fail, it could stall attempts to improve carbon emissions. This is likely to act as a brake upon those who would see draconian legislation to reduce flights.

The most likely outcome is, as usual, control by inactivity. The development of new airport capacity already lags projected demand dramatically. The ludicrously extended planning enquiry for Terminal 5 at Heathrow demonstrates that the flow of new capacity is likely to be sporadic at best.

The corollary to this is increasing congestion at the main hubs across Europe and decanting of surplus demand to regional airports. For example, movements at Heathrow are capped at 480,000 per annum. In 2007, the airport is expected to operate at 99 per cent capacity by this measure.

In part, this congestion will be handled by better management of air traffic control through the 'Single European Sky' proposals and better-slot allocation. A key plank in this strategy is to make better use of regional airports to absorb some of the capacity; however, this flies in the face of 
industry demand that, broadly, sees consolidation into existing hubs as the key to greater efficiency.

Retailers need to be where the passengers are and while established hubs like Heathrow and Gatwick are likely to continue to offer critical mass in this respect, opportunities may arise to improve the retail offer at regional airports.

\section{References and Notes}

1. Verdict Research Ltd (2007). Global Airport Retailing 2007, Verdict Research Ltd., London.

2. ACI \& York aviation (2004), The social and economic impacts of airports in Europe. Available from http://www.google.com/search?q=cache:s3vY_JYganQJ:www.aci-europe.org/upload/The\% 2520 social\%2520and\%2520economic\%2520impact\%2520of\%2520airports\%2520in\%2520Euro pe.pdf+York+Aviation+\%E2\%80\%93+The+social+and+economic+impacts+of+airports+in+ Europe+\%E2\%80\%93+ACI+\%E2\%80\%93+Geneva+\%E2\%80\%93+2004\&hl=en\&ct= clnk\&cd=2\&gl=uk.

3. Kasarda, J.D. (2000). Aerotropolis: Airport-driven urban development. ULI on the Future: Cities in the 21st Century, Urban Land Institute, Washington, DC.

4. Airbus (2004). Global Market Forecasts 2004 - 2023. Available from http://www.airbus.com/ en/corporate/gmf.

5. Boeing (2007). Market Forecasts. Available from http://www.boeing.com/commercial/cmo.

6. Eurocontrol (2004). Long-Term Forecasts of Flights. Available from http://www.eurocontrol.int/ statfor/public/standard_page/forecast_reports.html.

7. Air Transport Action Group (2000). European Air Traffic Forecasts. Avaialbe from http://www. atag.org/files/EuropAirTrafficForecastsP1.pdf.

8. IATA (2006). World Air Transport Statistics, 50th edn. Available from http://www.iata.org/ps/ publications/9011.htm.

9. HM Treasury (2006). Stern Review on the Economics of Climate Change, Cambridge University Press, Cambridge.

10. The net income consists of commercial income at airport level plus duty-free profits apportioned at airport level using passenger throughput.

11. In this case, retail income less apportioned entertainment, car hire and duty-free goods. 